\title{
Effect of smoking on vitamin A, vitamin E, and other trace elements in patients with cardiovascular disease in Bangladesh: a cross-sectional study
} Sam K Bashar ${ }^{1}$ and Amal K Mitra*2

Address: ${ }^{1}$ North South University, Dhaka, Bangladesh and ${ }^{2}$ Department of Community Health Sciences, The University of Southern Mississippi, Hattiesburg, MS, USA

Email: Sam K Bashar - skbashar@northsouth.edu; Amal K Mitra* - amal.mitra@usm.edu

* Corresponding author

Published: 05 October 2004

Nutrition Journal 2004, 3:18 doi:10.1186/1475-289|-3-18

This article is available from: http://www.nutritionj.com/content/3/I/l8

(c) 2004 Bashar and Mitra; licensee BioMed Central Ltd.

This is an open-access article distributed under the terms of the Creative Commons Attribution License (http://creativecommons.org/licenses/by/2.0), which permits unrestricted use, distribution, and reproduction in any medium, provided the original work is properly cited.
Received: 26 August 2004

Accepted: 05 October 2004

\begin{abstract}
Background: Data regarding the impact of cigarette smoking on trace elements are scarce and inconsistent. In this study, we evaluated the effect of smoking on serum concentrations of trace elements among adult males with heart disease.

Methods: This cross-sectional study included 100 adults hospitalized with heart disease in Bangladesh. The major variables of interest included mean serum concentrations of trace elements and proportion of subjects with bacterial growth on throat swab culture.

Results: Smokers had significantly lower serum concentrations of retinol, alpha-tocopherol, selenium, and zinc and increased concentrations of copper. Throat swab cultures were more often positive for Streptococcus $\beta$-hemolyticus in smokers than controls.
\end{abstract}

Conclusions: Smoking decreases serum concentrations of trace elements. Smoking control programs are needed in Bangladesh to improve health and nutrition of the people who are already nutritionally deficient.

\section{Introduction}

Smoking is a widely accepted practice in Bangladeshi men and is associated with socialising, sharing, and male identity [1]. According to an earlier cross-sectional study, approximately $50 \%$ of males and $3 \%$ of females are tobacco smokers in Bangladesh [2]. Although smoking is a recognized risk factor for several diseases including emphysema, chronic bronchitis, cardiovascular diseases, and cancer [3-5], very little is known about the nutritional consequences of smoking. In animal models, administration of benzo(a)pyrene, a constituent present in cigarette smoke induced vitamin A depletion [6]. Vitamin A deficiency per se causes emphysema. Some other trace ele- ments, such as iron, zinc, and vitamin $\mathrm{E}$ were found to be deficient among healthy smokers compared to non-smokers. However, the available data are inconsistent regarding the effect of smoking on trace elements. In this study, we documented the effect of different doses of smoking on trace elements among hospitalized patients with heart disease in Bangladesh.

\section{Methods and Materials}

A cross-sectional study was conducted among 100 male patients admitted to the National Institute of Cardiovascular Disease (NICVD), Dhaka, Bangladesh from January through December 1998, after obtaining informed 
consent from the participants. The study protocol was reviewed and approved by the Human Subjects Ethical Committee of the NICVD. The patients who had a history of smoking 10 or more cigarettes per day were considered smokers, and those who never smoked were controls. All the patients, including controls, were admitted with heart disease. The study did not include females in this study because smoking is not a norm among females in that society. All the smokers and the first 20 of the non-smokers who met the selection criteria were eligible for the study. This study included only heavy smokers who smoked at least 10 sticks per day, and excluded mild or casual smokers to leave a buffer zone of comparison between smokers and non-smokers. Patients were stratified according to their smoking status as follows: Control $(n=20)$, non-smokers; Grade I $(n=20), 10$ - 15 sticks/ day; Grade II $(n=30), 16$ - 20 sticks/day; Grade III $(n=$ 30), 21 and more sticks/day.

Body weight and height were measured at admission. Weight $(\mathrm{kg})$ was measured to the nearest $0.1 \mathrm{~kg}$, with participants wearing light clothing and no shoes and using a beam balance with non-detachable weights. Height $(\mathrm{cm})$ was measured with a stadiometer to the nearest $0.5 \mathrm{~cm}$. Body mass index (BMI) was calculated using the following formula: weight $(\mathrm{kg}) /$ height $(\mathrm{m})^{2}$. Five $\mathrm{ml}$ of venous blood was obtained from each patient at admission in a test-tube, which was wrapped with aluminum foil to avoid degradation of vitamin A in light. Serum samples were separated by centrifugation, and kept stored at $-20^{\circ} \mathrm{C}$ until further analysis. For the analyses of trace elements, serum samples were stored at separate ion-free vials. Throat swab cultures were detected for the growth of bacteria.

\section{Laboratory Methods}

Serum retinol (vitamin A) and serum $\alpha$-tocopherol (vitamin E) concentrations were determined by high performance liquid chromatography (HPLC) according to Bieri et al. [7]. In brief, serum retinol and $\alpha$-tocopherol were extracted with hexane after deproteinization with abso- lute ethanol containing retinyl acetate and $\alpha$-tocopherol acetate (Sigma Chemical Co., St Louis, MO, USA) as internal standards for retinol and $\alpha$-tocopherol respectively. Retinol and $\alpha$-tocopherol were separated by HPLC (model PU 4010; Pye-Unicam) on a reverse-phase $\mathrm{C}_{18}$ column using methanol-water $(97.5: 2.5, \mathrm{v} / \mathrm{v})$ as the mobile phase. Coefficient of variation $(\mathrm{CV})$ values of ten replicates from a pooled serum sample for retinol and $\alpha$-tocopherol were 2.3 and $3.3 \%$ respectively.

Serum zinc was measured by flame atomic absorption spectrophotometry (AAS, Analyst 800, Perkin-Elmer, Norwalk, CT, USA) using a modification of the method described by Kirgbright [8]. Serial replication of aliquots from a pooled serum sample and quality control sera were used to check the precision and accuracy of the analytical methods. The within-run CV for zinc in a pooled serum sample was between 2.2 and $4 \%$, based on six to seven samples in each of the five runs. Serum concentrations of copper and selenium were measured by the AAS method mentioned above.

\section{Statistical Methods}

Data were analyzed using SPSS for windows, version 11.0 (SPSS Inc., Chicago, IL). Descriptive statistics of the major variables of interest were calculated to determine the distribution of the data. All the variables except serum iron concentrations were normally distributed. Variables between smokers and non-smokers were compared by Student t-test for continuous data and by Chi-square test for categorical data. A probability level of 5\% was considered statistically significant.

\section{Results}

Of the 110 patients enrolled, 10 dropped out; eight had incomplete data, one withdrew early, and one left the hospital without notice. The mean \pm SD age of the study patients was $43.67 \pm 6.79 \mathrm{y}$ (range, $28-57 \mathrm{y}$ ). The groups did not differ significantly in terms of age and anthropometric measurements (Table 1).

Table I: Baseline characteristics of the study subject

\begin{tabular}{|c|c|c|c|c|c|}
\hline & \multirow[t]{2}{*}{ Control (Non-smoker) $n=20$} & \multicolumn{3}{|c|}{ Smoker } & \multirow[t]{2}{*}{ All $n=100$} \\
\hline & & $\begin{array}{c}\text { Grade I I0-15 sticks/d } \\
\qquad n=20\end{array}$ & $\begin{array}{c}\text { Grade II I6-20 sticks/d } \\
\qquad n=30\end{array}$ & $\begin{array}{c}\text { Grade III } 21+\text { sticks } / d \\
n n=30\end{array}$ & \\
\hline Age (year) & $41.60 \pm 8.30$ & $44.40 \pm 7.52$ & $43.57 \pm 5.85$ & $44.67 \pm 6.06$ & $43.67 \pm 6.79$ \\
\hline Weight (kg) & $60.95 \pm 3.32$ & $63.25 \pm 3.40$ & $62.50 \pm 3.64$ & $62.90 \pm 2.81$ & $62.46 \pm 3.34$ \\
\hline Height (m) & $1.64 \pm 0.03$ & $1.65 \pm 0.03$ & $1.65 \pm 0.03$ & $1.63 \pm 0.04$ & $1.65 \pm 0.03$ \\
\hline BMI & $22.32 \pm 1.35$ & $23.11 \pm 1.31$ & $22.90 \pm 1.63$ & $23.17 \pm 1.10$ & $22.91 \pm 1.38$ \\
\hline
\end{tabular}

Values are mean $\pm S D$. 
Table 2: Effect of smoking on serum concentrations of retinol, alpha-tocopherol and other trace elements

\begin{tabular}{lcccc}
\hline Trace element $(\mu \mathrm{mol} / \mathrm{L})$ & Control (Non-smoker) $n=20$ & \multicolumn{3}{c}{ Smoker } \\
\cline { 3 - 5 } & & $\begin{array}{c}\text { Grade I I0-15 sticks/d } \\
n=20\end{array}$ & $\begin{array}{c}\text { Grade II I6-20 sticks/d } \\
n=30\end{array}$ & $\begin{array}{c}\text { Grade III 2I+ sticks/d } \\
n=30\end{array}$ \\
\hline Retinol & & $.66 \pm .12$ & $.45 \pm .09 *$ & $.28 \pm .07^{*}$ \\
Alpha-tocopherol & $.72 \pm .06$ & $10.0 \pm .7^{* *}$ & $8.6 \pm 1.9^{* * *}$ & $7.9 \pm 1.2^{* * *}$ \\
Copper & $13.5 \pm 1.6$ & $.46 \pm .16$ & $.61 \pm .19^{*}$ & $.62 \pm .27^{*}$ \\
Selenium & $.44 \pm .25$ & $.004 \pm .00 I^{*}$ & $.003 \pm .00 I^{*}$ & $.003 \pm .00 I^{*}$ \\
Zinc & $.013 \pm .001$ & $.46 \pm .15$ & $.46 \pm .20$ & $.42 \pm .15^{*}$ \\
\hline
\end{tabular}

Values are mean $\pm S D . * P<.05 ; * * P<.01 ; * * * P<.001$ compared with the control.

Table 3: Effect of smoking on bacterial growth on throat swab culture

\begin{tabular}{lcccc}
\hline Organism & Control (Non-smoker) $n=20$ & \multicolumn{2}{c}{ Smoker } \\
\cline { 3 - 5 } & & $\begin{array}{c}\text { Grade I I0-15 sticks/d } \\
n=20\end{array}$ & $\begin{array}{c}\text { Grade II I6-20 sticks/d } \\
n=30\end{array}$ & $\begin{array}{c}\text { Grade III 2I+ sticks/d } \\
n=30\end{array}$ \\
\hline Streptococcus $\beta$ hemolytica & 2.8 & 70.5 & 71.4 & 72.5 \\
Aerobacter aerogenes & 12.2 & 25.4 & 26.7 & 27.0 \\
No growth & 85.0 & 4.1 & 1.9 & 1.0 \\
\hline
\end{tabular}

Values are percentages. $P<.00 \mathrm{I}$ for all values of smokers compared with the control.

Serum retinol concentrations were below normal $(0.70$ $\mu \mathrm{mol} / \mathrm{L})$ among all smokers and the majority $(60 \%)$ of the controls. Table 2 shows that the smokers who smoke 16 sticks or more cigarettes per day had significantly lower concentrations of serum retinol compared with controls. Percentage decrease of alpha-tocopherol was most striking of all the trace elements. Zinc concentrations did not change among grade I and grade II smokers but decreased among grade III smokers compared with controls. Concentrations of copper increased but selenium decreased among smokers than controls.

A significantly higher proportion of smokers compared with controls had bacterial growth on their throat cultures, mostly due to Streptococcus $\beta$-hemolyticus (Table 3).

\section{Discussion}

In this study, adult male smokers with heart disease had significantly decreased serum concentrations of retinol, alpha-tocopherol, and selenium, and increased concentrations of copper, compared to non-smokers. Depression of trace elements in blood was more with increasing doses of smoking.

In a study in Turkey, plasma selenium, copper, zinc and iron concentrations, and the activities of related erythrocyte antioxidative enzymes copper-zinc superoxide dis- mutase (Cu-Zn SOD), catalase, and glutathione peroxidase (GSH-Px) were measured in tobacco smokers and compared with those of nonsmokers [9]. Plasma thiocyanate levels were measured as an index of smoking status. While plasma copper concentration and erythrocyte $\mathrm{Cu}-\mathrm{Zn}$ SOD activity were significantly higher, plasma selenium concentration and erythrocyte GSH-Px activities were significantly lower in tobacco smokers than in nonsmokers. We did not measure antioxidative enzyme levels in blood; however, our study had consistency with earlier findings of decreased serum concentrations of selenium and increased concentrations of copper among smokers. Kocyigit et al. [9] did not observe any significant effect of smoking on zinc or iron status. Our observation of a significantly depressed zinc status only among heavy smokers (those who smoked 21 or more sticks per day) compared to non-smokers was consistent with findings of Uz et al. in Turkey [10].

Several studies documented that smoking may increase oxidative stress and impair oxidant defense system [11]. Serum selenium glutathione peroxidase, glutathione reductase, and extracellular superoxide dismutase activities were found lower in smokers than in non-smokers. Serum ascorbic acid and folate concentrations were lower in smokers than in non-smokers, whereas serum thiobarbituric acid-reactive substances (TBARS) were higher. 
However, Kim et al. (2003) did not observe any effect of smoking on serum copper, iron, and magnesium concentrations [11].

In a later study, Kim et al. (2004) further evaluated the influence of short- and long-term cigarette smoking on blood antioxidant status among Korean teenage girls (aged 14 to $18 \mathrm{y}$ ) and adult males (aged 36 to $51 \mathrm{y}$ ) [12]. Extracellular superoxide dismutase activities and concentrations of serum vitamin $\mathrm{C}$ and folate were lower in both short-term and long-term smokers. Serum copper concentrations were higher only among long-term smokers compared to non-smokers. In our study, we observed increased serum concentrations of copper among grade II and grade III smokers (those who smoked 16 or more sticks per day) but not among grade I smokers (those who smoked 10-15 sticks per day), as compared to non-smokers. Both the studies suggest that probably an increasing dose of smoking modify serum copper status more compared to those who smoke less or do not smoke at all. However, cigarette smoking, irrespective of dose or duration, had negative effects on antioxidant status in the Korean study [12].

Increasing evidence suggests that smoking is a causal factor for coronary heart disease and stroke. In a prospective study in Japan [4], 19,782 men and 21,500 women aged 40 to 59 years who were free of prior diagnosis of stroke, coronary heart disease, or cancer and reported their smoking status were followed. During a 461,761 person-year follow-up, relative risks (95\% CIs) for current smokers compared with never-smokers were 1.27 (1.05 to 1.54) for total stroke, 0.72 (0.49 to 1.07) for intraparenchymal hemorrhage, 3.60 (1.62 to 8.01) for subarachnoid hemorrhage, and 1.66 (1.25 to 2.20) for ischemic stroke.

One of the limitations of our study is that it is difficult to establish any causal association of heart disease and deficiency of trace elements or increased isolation of Streptococcus $\beta$-hemolyticus among our study subjects, because it is a cross-sectional study. However, epidemiologic evidence has suggested a modifying role for antioxidant micronutrients, including tocopherols and carotenoids, in atherosclerosis and heart disease. In an experimental study, Handelman et al. (1996) exposed freshly obtained human plasma to the gas phase of cigarette smoke to assess its effects on tocopherols, carotenoids, and retinol. Exposure to cigarette smoke led to the depletion of most of the lipophilic antioxidants in human plasma [13].

In addition to the impact on health, tobacco smoking represents a major economic burden for impoverished Bangladeshis. Average male cigarette smokers spend more than twice as much on cigarettes as per capita expenditure on clothing, housing, health and education combined. The typical poor smoker could easily add over 500 calories to the diet of one or two children with the daily tobacco expenditure [14]. It may be noted that most of the study subjects were undernourished, as indicated by an average BMI of 23. Strong tobacco control measures are needed in the context of Bangladesh to decrease tobacco expenditures and thus significantly increase resources and improve health and nutrition of the people.

\section{Conclusion}

This study demonstrated that increasing amount of cigarette smoking negatively impact serum concentrations of retinol, alpha-tocopherol, selenium, and zinc. Cigarette smoking may act as an important adjunct to the deficiency of those trace elements in a population who are already nutritionally compromised.

\section{Competing interests}

The authors declare that they have no competing interests.

\section{Authors' contributions}

SKB participated in the design of the study and collected the samples. AKM performed the statistical analysis and drafted the manuscript.

\section{Acknowledgements}

The authors are thankful to the staff including Nurun Nahar Sultana of the Department of Biochemistry, University of Dhaka, Bangladesh for their contribution in data collection and the biochemical analysis of blood samples. Written consent was obtained from the patient or their relative for publication of study.

\section{References}

I. Bush J, White M, Kai J, Rankin J, Bhopal R: Understanding influences on smoking in Bangladeshi and Pakistani adults: Community based, qualitative study. BMJ 2003, 326:962.

2. Zaman MM, Yoshiike N, Rouf MA, Syeed MH, Khan MR, Haque S, Mahtab H, Tanaka H: Cardiovascular risk factors: Distribution and prevalence in a rural population of Bangladesh. J Cardiovasc Risk 200I, 8:103-108.

3. Snyder LD, Eisner MD: Obstructive lung disease among urban homeless. Chest 2004, 1 25: 1719-1725.

4. Mannami T, Iso H, Baba S, Sasaki S, Okada K, Konishi M, Tsugane S: Japan Public Health Center-based Prospective Study on Cancer and Cardiovascular Disease Group. Cigarette smoking and risk of stroke and its subtypes among middle-aged Japanese men and women: the JPHC Study Cohort I. Stroke 2004, 35: 1248-1253.

5. Bain C, Feskanich D, Speizer FE, Thun M, Hertzmark E, Rosner BA, Colditz GA: Lung cancer rates in men and women with comparable histories of smoking. I Natl Cancer Inst 2004, 96:826-834.

6. Li T, Molteni A, Latkovich P, Castellani W, Baybutt RC: Vitamin A depletion induced by cigarette smoke is associated with the development of emphysema in rats. J Nutr 2003, 133:2629-2634.

7. Bieri JG, Tolliver TJ, Catignani GL: Simultaneous determination of alpha-tocopherol and retinol in plasma or red cells by high pressure liquid chromatography. Am J Clin Nutr 1979, 32:2143-2। 49 .

8. Kirgbright GF: Atomic absorption spectroscopy. Elemental analysis of biological materials. Vienna Technical Report Series. Int Atomic Agency 1980, 197:141-165.

9. Kocyigit A, Erel O, Gur S: Effects of tobacco smoking on plasma selenium, zinc, copper and iron concentrations and related antioxidative enzyme activities. Clin Biochem 200I, 34:629-633. 
10. Uz E, Sahin S, Hepsen IF, Var A, Sogut S, Akyol O: The relationship between serum trace element changes and visual function in heavy smokers. Acta Ophthalmol Scand 2003, 81:16I-164.

II. Kim SH, Kim JS, Shin HS, Keen CL: Influence of smoking on markers of oxidative stress and serum mineral concentrations in teenage girls in Korea. Nutrition 2003, 19:240-243.

12. Kim SH, Ensunsa JL, Zhu QY, Kim JS, Shin HS, Keen CL: An I8month follow-up study on the influence of smoking on blood antioxidant status of teenage girls in comparison with adult male smokers in Korea. Nutrition 2004, 20:437-444.

13. Handelman GJ, Packer L, Cross CE: Destruction of tocopherols, carotenoids, and retinol in human plasma by cigarette smoke. Am J Clin Nutr 1996, 63:559-565.

14. Efroymson D, Ahmed S, Townsend J, Alam SM, Dey AR, Saha R, Dhar $B$, Sujon Al, Ahmed KU, Rahman O: Hungry for tobacco: An analysis of the economic impact of tobacco consumption on the poor in Bangladesh. Tobacco Control 200I, 10:212-2 17.

Publish with Bio Med Central and every scientist can read your work free of charge

"BioMed Central will be the most significant development for disseminating the results of biomedical research in our lifetime. "

Sir Paul Nurse, Cancer Research UK

Your research papers will be:

- available free of charge to the entire biomedical community

- peer reviewed and published immediately upon acceptance

- cited in PubMed and archived on PubMed Central

- yours - you keep the copyright

Submit your manuscript here:

http://www.biomedcentral.com/info/publishing_adv.asp 